\title{
Assessing Hyperspectral Vegetation Indices Responses of Six Pigweed Species
}

\author{
Reginald S. Fletcher \\ United States Department of Agriculture, Agricultural Research Service, Stoneville, USA \\ Email: reginald.fletcher@usda.gov
}

How to cite this paper: Fletcher, R.S. (2020) Assessing Hyperspectral Vegetation Indices Responses of Six Pigweed Species. American Journal of Plant Sciences, 11, 1934-1948.

https://doi.org/10.4236/ajps.2020.1112138

Received: September 23, 2020

Accepted: December 11, 2020

Published: December 14, 2020

Copyright $\odot 2020$ by author(s) and Scientific Research Publishing Inc. This work is licensed under the Creative Commons Attribution International License (CC BY 4.0).

http://creativecommons.org/licenses/by/4.0/

(c) (i) Open Access

\begin{abstract}
Pigweeds (Amaranthus species), negatively impact crop production systems throughout the world. They are distinguished from each other using manual methods that are tedious and time-consuming to complete. Hyperspectral light reflectance properties of plant leaves and canopies have shown promise for detecting and mapping weeds in crop production systems. Vegetation indices derived from hyperspectral reflectance data enhance differences between plants, leading to better detection of them from other targets. The objective was to evaluate the biomass and structural index, the biochemical index, the red edge index, the water and moisture index, the light-use efficiency index, and the lignin cellulose index for measuring differences among six pigweed species: Amaranthus albus (L), A. hybridus (L), A. palmeri (S. Wats.), A. retroflexus (L), A. spinosus (L), and A. tuberculatus [(Moq.) Sauer]. Two experiments were conducted under greenhouse conditions. Hyperspectral reflectance measurements were collected from the plant canopies on two dates for each experiment. Analysis of variance (ANOVA) and Tukey's honest significant difference (HSD) test were used to determine if statistical differences $(P \leq 0.05)$ existed among the pigweed species canopies and to identify which species were statistically different for a vegetation index, respectively. The ANOVA analysis detected statistical differences among the canopy vegetation index values. Tukey's HSD showed that the biochemical index and the red edge index detected differences between two to three pigweeds species on all dates of data collection. However, the differences were date-specific. Furthermore, statistical differences were not observed for all six species for any vegetation index. On the data collection dates, A. albus and $A$. tuberculatus index values were statistically different from other pigweed species for one or more of the vegetation indices. Future research should focus on using the vegetation indices in combination with each other to measure differences between the pigweed species and between them and other weeds and crops.
\end{abstract}




\section{Keywords}

Hyperspectral, Palmer Amaranth, Remote Sensing, Weeds

\section{Introduction}

Pigweeds (Amaranthus spp.) negatively impact crop production systems in the United States and throughout the world [1] [2] [3] [4] [5]. They grow fast and compete with crops for light, water, and nutrients [6]. Pigweeds serve as host plants for crop pests, including insects, viruses, and fungi [7] [8]. Their pollen can cause an allergic reaction to sensitive individuals [9] [10]. Pigweeds known to cause problems in agriculture are Amaranthus albus, A. blitoides, A. hybridus, A. palmeri, A. powelli, A. retroflexus, A. spinosus, and A. tuberculatus [5] [6]. They have developed resistance to herbicides used in crop production systems [5].

Weed distribution surveys are often done manually, which can be laborious, especially if a lot of hectares need surveying. Different pigweed species are commonly found growing together in the same field. They are distinguished from each other using manual methods, which are time-consuming. Ref [11] indicated that it is difficult to differentiate between pigweeds before flowering and that at maturity distinguishing between them is less complicated, but not altogether straight forward. Thus, for this study, it is proposed to use hyperspectral vegetation indices to differentiate between pigweed species.

Hyperspectral data are captured at numerous narrowband contiguous wavelengths. Hyperspectral light reflectance data acquired from plant leaves and canopies have shown promise for differentiating between plants. Furthermore, vegetation indices derived with hyperspectral reflectance data have enhanced plant mapping and separation of plants from other targets [12] [13] [14].

A vegetation index is a mathematical combination or transformation of two or more spectral bands of data. They provide information on vegetation condition, status, and health, accentuate green plants spectral properties so that the plants appear distinct from other features, and allow reliable spatial and temporal comparisons of photosynthetic activity and canopy structural variations [15] [16] [17] [18]. Vegetation indices have shown the ability to estimate plant biomass, leaf area index, and pigment concentration, to detect plant stress, and to determine plant management practices influences on plant growth and development [17]. Vegetation indices derived from the narrow bands of hyperspectral data allow the user to better tune in the plant characteristics mentioned above and are referred to as narrowband or hyperspectral vegetation indices [17] [19]. In a pre-plant weed detection study, seven hyperspectral vegetation indices were more effective than single-band data in separating weeds from nontargets such as residue and bare soil [14]. Compared with broadband vegetation indices, hyperspectral narrowband vegetation indices have been documented to improve 
estimates of vegetation and agricultural crops biophysical and biochemical parameters [15] [17] [19].

Hyperspectral vegetation indices have been separated by researchers into six categories: biomass and structural indices, biochemical indices, red edge indices, water and moisture indices, light-use efficiency index, and lignin and cellulose index. The biomass and structure indices values correlate well with plant biomass, leaf area index, plant height, and grain yield [19] [20]. The biochemical indices have shown promise for assessing plant pigments such as carotenoids, anthocyanins, and chlorophyll and for detecting nitrogen deficiency in plants [21] [22]. The red edge indices have been useful for monitoring plant stress and drought [20]. The water and moisture indices have shown promise for measuring plant water content of plants [19] [20]. The light use efficiency index is best for monitoring photosynthetic activity of plants [23] [24] [25]. The lignin and cellulose index has been useful for estimating plant lignin and cellulose content and plant residue [20].

Currently, an information gap exists in using hyperspectral remotely sensed vegetation indices to differentiate between pigweed species based on their canopy architecture. The objective of this study was to evaluate the biomass and structural index, the biochemical index, the hyperspectral red edge index, the water and moisture index, the light-use efficiency index, and the lignin cellulose index for measuring differences among Amaranthus albus, A. hybridus, A. palmeri, A. retroflexus, A. spinosus, and $A$. tuberculatus grown under the same environmental conditions. If researchers, producers, and consultants could differentiate between pigweeds using hyperspectral vegetation indices, then they would have a better understanding of pigweed populations in fields, leading to better management decisions.

\section{Methods and Methods}

\subsection{Experimental Background}

The study was conducted in a greenhouse at the United States Department of Agriculture, Agricultural Research Service facility located in Stoneville, MS (33.424673 ${ }^{\circ}$ Latitude, $-90.912048^{\circ}$ Longitude). Planting dates were October 11, 2019, and December 12, 2019, for experiments one and two, respectively. Seeds of each pigweed species (A. albus, A. hybridus, A. palmeri, A. retroflexus, A. spinosus, and $A$. tuberculatus) were planted in a $10.16 \mathrm{~cm}$ square form pot (Greenhouse Mega Store, Danville, IL) filled with commercial potting mix (Pro Mix BX, Premier Tech Horticulture, Quakertown, PA) and allowed to emerge and grow to the two-leaf stage prior to transplanting a single plant into a seed tray [22.86 cm (length) $\times 16.51 \mathrm{~cm}$ (width) $\times 6.35 \mathrm{~cm}$ (height), Garland, Products Limited, Kingswinford, England] containing commercial potting mix (same mix used to plant the seeds). The seeds were obtained through the United States National Plant Germplasm System (North Central Regional Plant Introduction Station, Ames, IA). After transplanting, the plants were arranged in a rando- 
mized complete block design consisting of 6 blocks and 6 treatments (i.e., each plant A. albus, A. hybridus, A. palmeri, A. retroflexus, A. spinosus, and A. tuberculatus).

\subsection{Greenhouse Conditions}

The greenhouse temperature was maintained between $20^{\circ} \mathrm{C}$ and $26.7^{\circ} \mathrm{C}$. Plants were subjected to a $14 \mathrm{hr}$. daylength. Between the hours of 0600 to 0800 and 1700 to 2000 , lighting was provided by sodium vapor lamps to supplement sunlight and provide light before sunrise and after sunset. Plants were watered when needed and fertilized weekly with a commercial fertilizer (Dyna-gro 777, Richmond, CA).

\subsection{Hyperspectral Measurements}

Hyperspectral reflectance measurements of the plant canopies were obtained with the FieldSpec 3 spectroradiometer (ASD, Malvern Panalytical, Westborough, MA) and the FieldSpec4 high-resolution spectroradiometer (ASD, Malvern Panalytical, Westborough, MA), for experiments one and two, respectively. Specifications for the FieldSpec 3 spectroradiometer were as follows: spectral range-350 - $2500 \mathrm{~nm}$; spectral resolution-3 nm @ $700 \mathrm{~nm}$ and $10 \mathrm{~nm} @$ 1400/2100 nm; sampling interval-1.4 nm @ 350 - 1050 nm and 2 nm @ 1000 $2500 \mathrm{~nm}$. Characteristics of the FieldSpec4 high-resolution spectroradiometer were as follows: spectral range-350 - $2500 \mathrm{~nm}$; spectral resolution-3 nm @ 700 nm and 8 nm @ 1400/2100 nm; spectral sampling-1.4 nm @ 350-1000 nm and $1.1 \mathrm{~nm} @ 1001-2500 \mathrm{~nm}$. The software used to operate the spectroradiometers automatically resamples the data into a $1 \mathrm{~nm}$ spectral resolution.

The hyperspectral reflectance measurements were obtained by placing the spectroradiometer's sensor $30 \mathrm{~cm}$ above the plant canopy, resulting in a $13.5 \mathrm{~cm}$ diameter field of view for the sensor. Each plant canopy reflectance value was an average of 15 reflectance readings, which is recommended to obtain good spectral outputs with the FieldSpec spectroradiometers [26]. For Experiment 1, the measurements were acquired on December 4 and December 18, 2019. Experiment 2 data collection dates were February 8 and February 27, 2020. The hyperspectral reflectance data were acquired under sunny conditions, $\pm 2 \mathrm{hrs}$. of solar noon outside of the greenhouse. The spectroradiometers were calibrated with a white spectralon panel at 15-minute intervals. Black felt was employed to cover the top portion of the plant tray and hide the potting mix surface and was used to cover the cart surface where the plant tray was placed to obtain the measurements [27]. This procedure was used to provide a uniform background for all spectral readings [27].

At the time of the hyperspectral measurements, the pigweed growth stages range from vegetative to flowering. The differences in growth stages occurred because the plants grew at different rates. For the measurements collected on the second date in both experiments, if the seed head of the pigweed plant was greater than $5 \mathrm{~cm}$, then the portion greater than $5 \mathrm{~cm}$ was clipped from the top 
of the plant. This action allowed the sensor viewing area to be equal for each plant measurement, as well as the integration of the seed head into the measurements.

\subsection{Post Processing of Spectral Measurements}

Post processing the spectral data involved three steps: 1) splice correction, 2) removal of noisy bands and bands commonly not used for remote sensing of plants, and 3) spectra smoothing with Savitsky-Golay filter [28]. Splice correction was used to eliminate gaps (errors) in the spectroradiometers' detector arrays signal occurring at $1000 \mathrm{~nm}$ and $1800 \mathrm{~nm}$ [26]. It was completed with the ViewSpec Pro software (Version 6.2; ASD Inc., Boulder CO). Wavelengths less than $400 \mathrm{~nm}$ (not commonly used for remote sensing of plants), water absorption bands (1330 - $1480 \mathrm{~nm}$ and $1788-1990 \mathrm{~nm}$, noisy due to strong water absorption), and noisy spectral bands (2350 - $2500 \mathrm{~nm}$, sensor noise) were removed from the spectral dataset. The Savitsky-Golay filter was used to smooth the spectra; $\mathrm{n}=25$ was applied as the filter smoothing value. Waveband removal and Savitsky-Golay filtering were achieved with the R software [29] package hsdar [30].

\subsection{Hyperspectral Vegetation Indices}

Hyperspectral vegetation indices for studying vegetation and agricultural crops have been separated into the following categories [16] [20]: biomass and structural indices, biochemical indices, red edge indices, water and moisture indices, light-use efficiency index, and lignin and cellulose index. For this study, one vegetation index within each category was tested for separating the pigweeds. To keep the comparison even, this study focused on using the highest ranked normalized difference version of the equation [19] within each category (Table 1). The selections only applied to the biomass and structural indices, the biochemical indices, the red edge indices, and the water and moisture indices because they consisted of more than one normalized difference index to choose from [19] [31]. Also, normalized difference vegetation index values range from

Table 1. Hyperspectral vegetation indices, and the center wavelengths and the bandwidths used to create the indices.

\begin{tabular}{|c|c|c|c|c|c|}
\hline Index & $\begin{array}{c}\mathrm{B}^{\mathrm{a}} \\
(\mathrm{nm})\end{array}$ & $\begin{array}{l}\mathrm{B} 1 \lambda \\
(\mathrm{nm})\end{array}$ & $\begin{array}{c}\text { B2 } \\
(\mathrm{nm})\end{array}$ & $\begin{array}{l}\mathrm{B} 2 \lambda \\
(\mathrm{nm})\end{array}$ & Equation \\
\hline Biomass and structural index & 855 & 20 & 682 & 5 & $(855-682) /(855+682)$ \\
\hline Biochemical index & 550 & 5 & 515 & 5 & $(550-515) /(550+515)$ \\
\hline Red edge index & 855 & 5 & 720 & 5 & $(855-720) /(855+720)$ \\
\hline Water and moisture index & 855 & 20 & 970 & 10 & $(855-970) /(855+970)$ \\
\hline Light use and efficiency index & 570 & 5 & 531 & 1 & $(570-531) /(570+531)$ \\
\hline Lignin and cellulose index & 2205 & 5 & 2025 & 1 & $(2205-2025) /(2205+2025)$ \\
\hline
\end{tabular}

a. $\mathrm{B}=$ band; $\lambda=$ bandwidth. 
negative one to positive one and these indices have the potential to normalize sun angle, topographic effects, and some atmospheric effects [32]. The vegetation indices were derived from the $1 \mathrm{~nm}$ hyperspectral data. The hsdar package in $\mathrm{R}$ software was used to resample the data to the appropriate wavelength and create the vegetation index value for the plant samples.

\subsection{Statistical Analysis}

Analysis of variance (ANOVA) [33] was used to measure the statistical difference $(P \leq 0.05)$ among pigweed group means for each vegetation index. Then Tukey's honest significant difference (HSD) [34] test was tabulated to identify which pigweed means were statistically different $(P \leq 0.05)$. Analyses were completed with the R software package agricolae [35] [36].

\section{Results}

\subsection{Spectral Response Curve}

Figure 1 shows the mean canopy hyperspectral reflectance curves of the pigweeds. Their spectral response patterns were typical for green plants. Reflectance increased in the visible green region of the spectrum (500 - $600 \mathrm{~nm})$. A steep increase in reflectance occurred in the red edge area, followed by a plateau in reflectance within the near infrared region. Two additional peaks were evident in the shortwave infrared section of the spectrum.

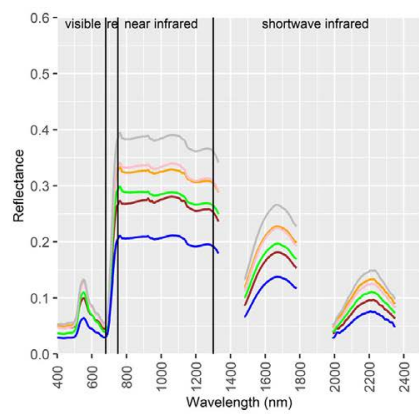

(A)

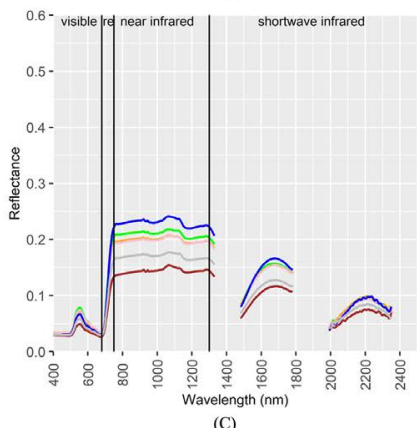

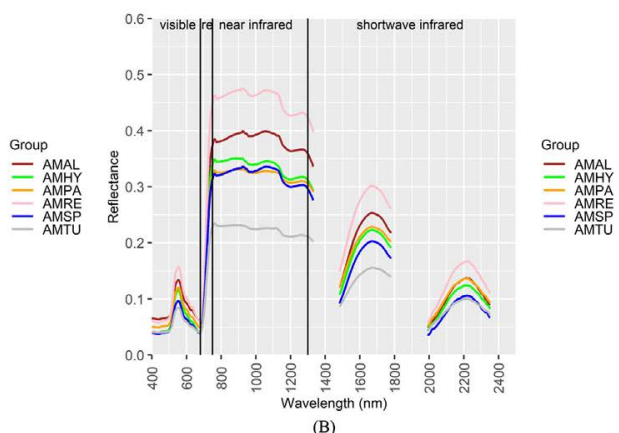

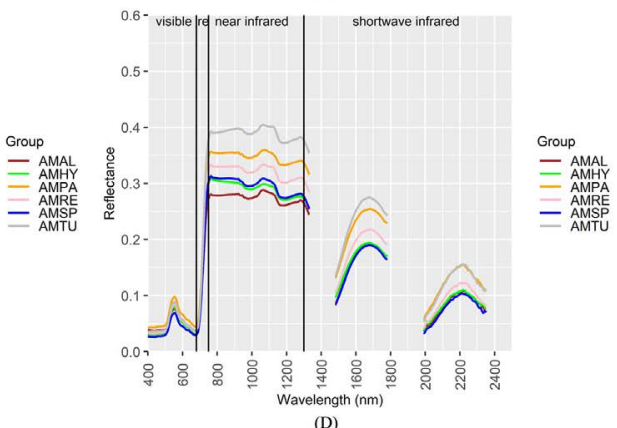

Figure 1. Mean canopy hyperspectral curves $(n=6)$ of pigweeds for experiment 1 , (A) December 4, 2019, and (B) December 18, 2019, and for experiment 2, (C) February 8, 2020, and (D) February 27, 2020. AMAL-Amaranthus albus, AMHY-A. hybridus, AMPA-A. palmeri, AMRE-A. retroflexus, AMSP-A. spinosus, and AMTU- $A$. tuberculatus, re-red edge. 
The near infrared region of the spectrum exhibited the greatest difference among the pigweed spectral responses. For the 2019 dataset on the first and second data collection dates, the greatest differences were between $A$. tuberculatus and A. spinosus and between A. retroflexus and A. tuberculatus, respectively. Noticeable contrasts occurred between $A$. spinosus and A. albus on February 8 and between A. tuberculatus and A. albus on February 27 for the 2020 measurements.

Apparent differences were also observed in the spectral responses of the pigweeds in the visible region and shortwave infrared part of the light spectrum. The differences were more evident in the shortwave infrared region compared with the visible region. Generally, an increase was seen in the plants' reflectance from the first date to the second date for both experiments. The only exception was $A$. tuberculatus in the first experiment.

\subsection{Statistical Results}

Table 2 summarizes the analysis of variance among treatment results for the experiments. Vegetation indices values varied among pigweed species with differences $(P<0.05)$ recorded based on date for the following indices: 1$)$ December 4, 2019-the biochemical index and the red edge index; 2) December 18, 2019-the biomass and structure index, the biochemical index, the red edge index, the water and moisture index, the light use and efficiency index, and the lignin and cellulose index; 3) February 8, 2020-the biomass and structure index, the biochemical index, the red edge index, the light use and efficiency index, and the lignin and cellulose index; and 4) February 27, 2020-the biomass and structure index, the biochemical index, the red edge index, the water and moisture index, and the lignin and cellulose index. On all measurement dates, statistically significant differences were identified among the pigweed mean values for the biochemical index and the red edge index.

Table 3 summarizes the Tukey's HSD results. The biochemical index and the red edge index measured a statistical difference between two or more pigweeds for each date of data collection. On December 4, 2019, A. hybridus was separable from $A$. spinosus and $A$. albus with the biochemical index; $A$. tuberculatus was distinguishable from $A$. palmeri with the red edge index. On December 18, 2019, $A$. hybridus and $A$. retroflexus biochemical index values were greater than $A$. tuberculatus biochemical index values, and $A$. albus biochemical index values were less than $A$. hybridus biochemical index values. The red edge index indicated that $A$. tuberculatus was distinguishable from A. spinosus. On February 8, 2020, a statistical difference was observed between $A$. albus and $A$. hybridus, $A$. spinosus, and $A$. palmeri for the biochemical index and between $A$. spinosus versus $A$. hybridus, $A$. palmeri, and A. retroflexus for the red edge index. On February 27, 2020, A. tuberculatus, A. hybridus, A. spinosus, and A. retroflexus biochemical index values were less than $A$. albus biochemical index values. Additionally, A. tuberculatus biochemical index values were greater than A.palmeri biochemical index values. Furthermore, a statistical difference existed between 
Table 2. Analysis of variance (ANOVA) statistics for vegetation indices based on treatments (pigweed species).

\begin{tabular}{|c|c|c|c|}
\hline Experiment & Date & Vegetation Index & ANOVA Statistic ${ }^{a}$ \\
\hline \multirow[t]{12}{*}{1} & December 4, 2019 & Biomass and structural index & $\mathrm{F}=0.70 ; P=0.63 ; \mathrm{df}=5,25$ \\
\hline & & Biochemical index & $\mathrm{F}=4.04 ; P=0.008 ; \mathrm{df}=5,25$ \\
\hline & & Red edge index & $\mathrm{F}=3.22 ; P=0.02 ; \mathrm{df}=5,25$ \\
\hline & & Water and moisture index & $\mathrm{F}=1.69 ; P=0.17 ; \mathrm{df}=5,25$ \\
\hline & & Light use and efficiency index & $\mathrm{F}=1.27 ; P=0.31 ; \mathrm{df}=5,25$ \\
\hline & & Lignin and cellulose index & $\mathrm{F}=0.39 ; P=0.85 ; \mathrm{df}=5,25$ \\
\hline & December 18, 2019 & Biomass and structural index & $\mathrm{F}=4.86 ; P=0.003 ; \mathrm{df}=5,25$ \\
\hline & & Biochemical index & $\mathrm{F}=6.26 ; P<0.001 ; \mathrm{df}=5,25$ \\
\hline & & Red edge index & $\mathrm{F}=3.62 ; P=0.01 ; \mathrm{df}=5,25$ \\
\hline & & Water and moisture index & $\mathrm{F}=2.77 ; P=0.04 ; \mathrm{df}=5,25$ \\
\hline & & Light use and efficiency index & $\mathrm{F}=3.39 ; P=0.02 ; \mathrm{df}=5,25$ \\
\hline & & Lignin and cellulose index & $\mathrm{F}=8.89 ; P<0.001 ; \mathrm{df}=5,25$ \\
\hline \multirow[t]{12}{*}{2} & February 8,2020 & Biomass and structural index & $\mathrm{F}=3.02 ; P=0.03 ; \mathrm{df}=5,25$ \\
\hline & & Biochemical index & $\mathrm{F}=4.07 ; P=0.008 ; \mathrm{df}=5,25$ \\
\hline & & Red edge index & $\mathrm{F}=6.74 ; P<0.001 ; \mathrm{df}=5,25$ \\
\hline & & Water and moisture index & $\mathrm{F}=2.0 ; P=0.11 ; \mathrm{df}=5,25$ \\
\hline & & Light use and efficiency index & $\mathrm{F}=3.09 ; P=0.03 ; \mathrm{df}=5,25$ \\
\hline & & Lignin and cellulose index & $\mathrm{F}=2.62 ; P=0.05 ; \mathrm{df}=5,25$ \\
\hline & February 27, 2020 & Biomass and structural index & $\mathrm{F}=12.18 ; P<0.001 ; \mathrm{df}=5,25$ \\
\hline & & Biochemical index & $\mathrm{F}=8.23 ; P<0.001 ; \mathrm{df}=5,25$ \\
\hline & & Red edge index & $\mathrm{F}=8.39 ; P<0.001 ; \mathrm{df}=5,25$ \\
\hline & & Water and moisture index & $\mathrm{F}=8.56 ; P<0.001 ; \mathrm{df}=5,25$ \\
\hline & & Light use and efficiency index & $\mathrm{F}=1.03 ; P=0.42 ; \mathrm{df}=5,25$ \\
\hline & & Lignin and cellulose index & $\mathrm{F}=7.68 ; P<0.001 ; \mathrm{df}=5,25$ \\
\hline
\end{tabular}

a. $\mathrm{df}$-degrees of freedom, F-F-value.

Table 3. Mean comparisons $(n=6)$ of the pigweed species for each vegetation index separated by experiment and date.

\begin{tabular}{|c|c|c|c|c|c|c|c|}
\hline Experiment & Date & $\mathrm{BSI}^{\mathrm{ab}}$ & BCI & REI & WMI & LUE & LCI \\
\hline \multirow{8}{*}{1} & December 4, & AMHY & AMHY & AMTU & AMHY & AMSP & AMTU \\
\hline & 2019 & $0.7370 \mathrm{a}$ & $0.2940 \mathrm{a}$ & $0.1974 \mathrm{a}$ & $0.0142 \mathrm{a}$ & $0.0027 \mathrm{a}$ & $0.3545 \mathrm{a}$ \\
\hline & & AMTU & AMRE & AMSP & AMSP & AMPA & AMRE \\
\hline & & $0.7363 \mathrm{a}$ & $0.2760 \mathrm{ab}$ & $0.1906 \mathrm{ab}$ & $0.0071 \mathrm{a}$ & $-0.0015 \mathrm{a}$ & $0.3487 \mathrm{a}$ \\
\hline & & AMRE & AMTU & AMAL & AMRE & AMHY & AMAL \\
\hline & & $0.7289 \mathrm{a}$ & $0.2695 \mathrm{ab}$ & $0.1768 \mathrm{ab}$ & $0.0063 \mathrm{a}$ & $-0.0017 \mathrm{a}$ & $0.3468 \mathrm{a}$ \\
\hline & & AMSP & AMPA & AMRE & AMTU & AMRE & AMHY \\
\hline & & $0.7130 \mathrm{a}$ & $0.2673 \mathrm{ab}$ & $0.1640 \mathrm{ab}$ & $0.0059 \mathrm{a}$ & $-0.0019 \mathrm{a}$ & $0.3425 \mathrm{a}$ \\
\hline
\end{tabular}




\section{Continued}

\begin{tabular}{|c|c|c|c|c|c|c|c|}
\hline & & AMPA & AMSP & AMHY & AMPA & AMAL & AMPA \\
\hline & & $0.7083 \mathrm{a}$ & $0.2328 \mathrm{~b}$ & $0.1581 \mathrm{ab}$ & $0.0042 \mathrm{a}$ & $-0.0030 \mathrm{a}$ & $0.3315 \mathrm{a}$ \\
\hline & & AMAL & AMAL & AMPA & AMAL & AMTU & AMSP \\
\hline & & $0.6948 \mathrm{a}$ & $0.2237 \mathrm{~b}$ & $0.1538 \mathrm{~b}$ & $0.0009 \mathrm{a}$ & $-0.0059 \mathrm{a}$ & $0.3222 \mathrm{a}$ \\
\hline & December 18, & AMHY & AMHY & AMSP & AMTU & AMPA & AMSP \\
\hline & 2019 & $0.7821 \mathrm{a}$ & $0.2914 \mathrm{a}$ & $0.2273 \mathrm{a}$ & $0.0205 \mathrm{a}$ & $0.0032 \mathrm{a}$ & $0.3793 \mathrm{a}$ \\
\hline & & AMSP & AMRE & AMAL & AMHY & AMTU & AMAL \\
\hline & & $0.7663 \mathrm{a}$ & $0.2751 \mathrm{ab}$ & $0.2211 \mathrm{ab}$ & $0.0142 \mathrm{ab}$ & $0.0025 \mathrm{a}$ & $0.3675 \mathrm{a}$ \\
\hline & & AMRE & AMSP & AMRE & AMPA & AMRE & AMHY \\
\hline & & $0.7600 \mathrm{a}$ & $0.2607 \mathrm{abc}$ & $0.2128 \mathrm{ab}$ & $0.0096 \mathrm{ab}$ & $-0.0013 \mathrm{a}$ & $0.3668 \mathrm{a}$ \\
\hline & & AMAL & AMPA & AMHY & AMRE & AMSP & AMRE \\
\hline & & $0.7158 \mathrm{ab}$ & $0.2472 \mathrm{abc}$ & $0.2071 \mathrm{ab}$ & $0.0077 \mathrm{ab}$ & $-0.0037 \mathrm{a}$ & $0.3581 \mathrm{a}$ \\
\hline & & AMPA & AMAL & AMPA & AMSP & AMAL & AMPA \\
\hline & & $0.7117 \mathrm{ab}$ & $0.2248 \mathrm{bc}$ & $0.1936 \mathrm{ab}$ & $0.0038 \mathrm{ab}$ & $-0.0046 \mathrm{a}$ & $0.3206 \mathrm{a}$ \\
\hline & & AMTU & AMTU & AMTU & AMAL & AMHY & AMTU \\
\hline & & $0.6451 \mathrm{~b}$ & $0.2099 \mathrm{c}$ & $0.18351 \mathrm{~b}$ & $-0.0011 b$ & $-0.0050 \mathrm{a}$ & $0.2463 \mathrm{~b}$ \\
\hline & February 8 & AMSP & AMHY & AMSP & AMSP & AMRE & AMSP \\
\hline 2 & 2020 & $0.7512 \mathrm{a}$ & $0.2492 \mathrm{a}$ & $0.2354 \mathrm{a}$ & $0.0036 \mathrm{a}$ & $0.0037 \mathrm{a}$ & $0.3174 \mathrm{a}$ \\
\hline & & AMHY & AMSP & AMAL & AMHY & AMAL & AMPA \\
\hline & & $0.7118 \mathrm{ab}$ & $0.2421 \mathrm{a}$ & $0.2078 \mathrm{ab}$ & $0.0022 \mathrm{a}$ & $0.0015 \mathrm{ab}$ & $0.2839 \mathrm{ab}$ \\
\hline & & AMPA & AMPA & AMTU & AMTU & AMPA & AMRE \\
\hline & & $0.7068 \mathrm{ab}$ & $0.2388 \mathrm{a}$ & $0.2021 \mathrm{ab}$ & $0.0018 \mathrm{a}$ & $0.0010 \mathrm{ab}$ & $0.2834 \mathrm{ab}$ \\
\hline & & AMRE & AMRE & AMPA & AMPA & AMSP & AMHY \\
\hline & & $0.6838 \mathrm{ab}$ & $0.2243 \mathrm{ab}$ & $0.1964 \mathrm{~b}$ & $-0.0005 \mathrm{a}$ & $-0.0010 \mathrm{ab}$ & $0.2736 \mathrm{ab}$ \\
\hline & & AMTU & AMTU & AMHY & AMRE & AMHY & AMAL \\
\hline & & $0.6718 \mathrm{ab}$ & $0.2140 \mathrm{ab}$ & $0.1808 \mathrm{~b}$ & $-0.0017 \mathrm{a}$ & $-0.0013 \mathrm{ab}$ & $0.2664 \mathrm{ab}$ \\
\hline & & AMAL & AMAL & AMRE & AMAL & AMTU & AMTU \\
\hline & & $0.6629 \mathrm{~b}$ & $0.1844 \mathrm{~b}$ & $0.1766 \mathrm{~b}$ & $-0.0066 \mathrm{a}$ & $-0.0032 b$ & $0.2326 \mathrm{~b}$ \\
\hline & February 27, & AMTU & AMTU & AMTU & AMSP & AMPA & AMSP \\
\hline & 2020 & $0.8159 \mathrm{a}$ & $0.2869 \mathrm{a}$ & $0.2946 \mathrm{a}$ & $0.0216 \mathrm{a}$ & $0.0068 \mathrm{a}$ & $0.4028 \mathrm{a}$ \\
\hline & & AMSP & AMHY & AMSP & AMHY & AMSP & AMAL \\
\hline & & $0.8134 \mathrm{a}$ & $0.2794 \mathrm{ab}$ & $0.2866 \mathrm{ab}$ & $0.0201 \mathrm{ab}$ & $0.0059 \mathrm{a}$ & $0.3873 \mathrm{ab}$ \\
\hline & & AMHY & AMSP & AMRE & AMRE & AMRE & AMRE \\
\hline & & $0.7995 \mathrm{a}$ & $0.2794 \mathrm{ab}$ & $0.2641 \mathrm{bc}$ & $0.0158 \mathrm{abc}$ & $0.0048 \mathrm{a}$ & $0.3692 \mathrm{abc}$ \\
\hline & & AMRE & AMRE & AMAL & AMPA & AMHY & AMTU \\
\hline & & $0.7946 \mathrm{ab}$ & $0.2789 \mathrm{ab}$ & $0.2590 \mathrm{bc}$ & $0.0114 \mathrm{bcd}$ & $0.0037 \mathrm{a}$ & $0.3634 \mathrm{abc}$ \\
\hline & & AMPA & AMPA & AMPA & AMAL & AMTU & AMHY \\
\hline & & $0.7649 \mathrm{bc}$ & $0.2509 \mathrm{bc}$ & $0.2493 \mathrm{c}$ & $0.0109 \mathrm{~cd}$ & $0.0035 \mathrm{a}$ & $0.3559 \mathrm{bc}$ \\
\hline & & AMAL & AMAL & AMHY & AMTU & AMAL & AMPA \\
\hline & & $0.7595 \mathrm{c}$ & $0.2302 \mathrm{c}$ & $0.2448 \mathrm{c}$ & $0.0063 \mathrm{~d}$ & $0.0032 \mathrm{a}$ & $0.3304 \mathrm{c}$ \\
\hline
\end{tabular}

a. For each vegetation index on a specific date, means within a column followed by different letters are statistically significantly different at $P \leq 0.05$ according to Tukey's honest significant difference test. b. BSI-biomass and structural index, BCI-biochemical index, REI—red edge index, WMI-water and moisture index, LUE-light use and efficiency index, LCI-lignin and cellulose index, AMAL-Amaranthus albus, AMHY-Amaranthus hybridus, AMPA-Amaranthus palmeri, AMRE-Amaranthus retroflexus, AMSP_Amaranthus spinosus, and AMTU-Amaranthus tuberculatus. 
A. tuberculatus versus A. retroflexus, A. albus, A. palmeri, and A. hybridus, and between $A$. spinosus versus $A$. palmeri and $A$. hybridus for the red edge vegetation index. A. tuberculatus and $A$. spinosus red edge vegetation index values were higher than the other pigweeds red edge vegetation index values.

The biomass and structure index and the lignin and cellulose index ranked second in detecting statistical differences between the pigweeds (Table 3). On the second date for experiment one, $A$. tuberculatus biomass and structure index values were less than $A$. hybridus, A. spinosus, and A. retroflexus biomass and structure index values. A. tuberculatus values were lower than the other pigweeds values for the lignin and cellulose index. Experiment two first date measurements indicated that a statistically significant difference existed between $A$. spinosus and $A$. albus for the biomass and structure index and between $A$. tuberculatus and A. spinosus for the lignin and cellulose index. On the second date for experiment two, A. spinosus biomass and structure index values, and lignin and cellulose index values were greater than $A$. albus biomass and structure index values and $A$. tuberculatus lignin and cellulose index values, respectively.

The water and moisture index ranked third among the vegetation indices for statistical differences between pigweeds (Table 3). Statistical differences were observed on two dates, December 18, 2019, and February 27, 2020, for experiments one and two, respectively. On the first date, $A$. tuberculatus values were larger than A. albus values. On the second date, A. spinosus and A. hybridus were higher than $A$. palmeri, $A$. albus, and $A$. tuberculatus, and $A$. retroflexus values were greater than $A$. tuberculatus values.

The light use and efficiency vegetation index ranked last among the vegetation indices for detecting statistical difference between the pigweeds (Table 3). For experiment two on the first date, $A$. retroflexus light use and efficiency index values were higher than $A$. tuberculatus light use and efficiency index values.

\section{Discussion}

Vegetation indices are sensitive to various plant canopy components. In this study, six pigweed species canopies were evaluated to determine their effects on six vegetation indices sensitive to plants' biophysical and biochemical parameters. The six pigweeds studied are problem weeds in agricultural system. Statistical differences were measured between the pigweeds' vegetation index values, thus rejecting the null hypothesis of no difference between the pigweed species canopies for a vegetation index. On the data collection dates, A. albus and A. tuberculatus vegetation index values were statistically different from one or more pigweed species. The biochemical index and the red edge index were the most consistent indices in measuring differences between the pigweeds. They obtained statistical differences between pigweed species for each data collection date.

The vegetation indices were derived from narrow spectral bands within the visible, the red edge, the near infrared, and the shortwave infrared regions of the spectrum (Figure 1). Major differences were observed between the pigweeds' spectral reflectance values in the visible, near infrared, and shortwave infrared 
regions (Figure 1). Leaf pigments (chlorophyll) are responsible for leaf and canopy reflectance responses in the visible region of the spectrum [17] [37]. Plant canopies' near infrared reflectance properties are affected by leaf area, leaf orientation, and biomass [37] [38]. Leaf moisture influences the shortwave infrared reflectance properties of plants [17] [37]. These differences played a role in the values obtained by the vegetation indices for each pigweed species (Table 1, Table 3; Figure 1).

Additionally, within plant canopy shadowing and background influenced the pigweeds canopy reflectance properties, and thus vegetation index values. Pigweed canopy images (Figure 2) acquired on December 4, 2019, show evidence of how the background was integrated into the plant canopy reflectance measurements. The more open spaces within the plant canopy, the more background and shadow were incorporated into the overall vegetation index response. For this study, those parameters caused a reduction in the vegetation index values. In real-world situations, the background will be soil and even other plants, thus increasing the challenges of separating pigweeds from each other and other plants.

As stated earlier, the plant growth stages ranged from vegetative growth to flowering. Over time the plants grew and added additional leaf layers. Additional leaf layers can result in more background being covered and in less canopy shadowing. Generally, increases in vegetation indices values from the first date to the second date were evident for the vegetation indices.

The pigweed separation was date dependent. These results are representative of everyday situations. Whether an aerial or ground-based remote sensing system is used for measurements, the day of collection will represent that point and time. Data collected a week later may present a different scenario because the plants will have grown, or another environmental factor may have stressed the plants. Therefore, differences among pigweeds will change from one date to the next. Other researchers testing vegetation indices in weed crop separation have also documented that differences were date dependent and affected by plant growth stage [39].
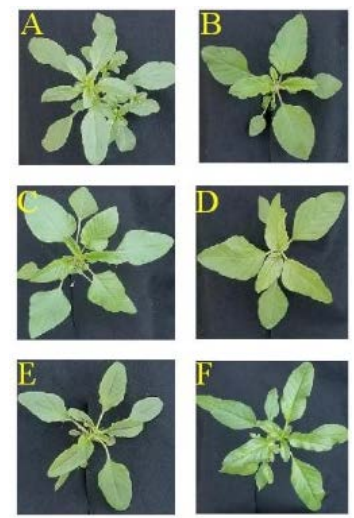

Figure 2. Pictures of pigweeds for experiment 1 acquired on December 4, 2019: (A) Amaranthus albus, (B) A. hybridus, (C) A. palmeri, (D) A. retroflexus, (E) A. spinosus, and (F) A. tuberculatus. 
Caution is needed when assessing vegetation index values, especially extremely low values. For example, the moisture stress index values measured statistical differences between four pigweed species (Table 3); however, the values were extremely low, close to zero. There may be a statistical difference, but that difference may not be transferable to practical applications.

For this study, plant seeds were secured through the United States National Plant Germplasm System. In fields, an additional factor to consider is the hybridization of two pigweed species. The newly developed plant can have characteristics of both parents. More information is needed on how pigweed hybridization affects vegetation index values.

Narrowband vegetation indices are designed to take advantage of the absorption and the non-absorption features of plants to provide estimates of plant biophysical and biochemical parameters [17]. That aspect was evident for the vegetation indices evaluated in this study. They contained a narrow spectral band that maximized the difference between pigweeds and one narrow spectral band in which the differences were minimal (Figure 1). Based on the absorption and the non-absorption concept, the vegetation indices distinguished between two to three pigweed species. Additionally, for the red edge index, shifts in the red edge position would occur for the different pigweed species due to differences in their chlorophyll content and leaf area. These shifts affect the slope of the spectral curve in the red edge region, and thus would have an impact on the red edge index values. Furthermore, the results suggest that a combination of narrowband vegetation indices may be the best avenue to pursue for separating pigweeds. Additional avenues are to explore other narrowband combinations for developing vegetation indices, to test derivative analysis, and to evaluate machine learning tools as a means for distinguishing between the pigweed species.

\section{Conclusion}

Narrowband remotely sensed vegetation indices designed to measure biophysical and biochemical properties of plants have potential for separating pigweed species. The biochemical index and the red edge index were the most consistent in pigweed species separation. To maximize pigweed separation in the future, it is believed that two or more vegetation indices should be used in an ensemble approach. Future research should focus on that concept and evaluating other spectral band combinations as indices for differentiating pigweed species from each other and other weeds and crops.

\section{Acknowledgements}

The author would like to thank Milton Gaston, Jr., for assisting in collecting the hyperspectral data. Mention of a trade name, proprietary product, or specific equipment does not constitute a guarantee or warranty by the United States Department of Agriculture and does not apply endorsement of a product to the exclusion of others that may be suitable. 


\section{Conflicts of Interest}

The author declares no conflicts of interest regarding the publication of this paper.

\section{References}

[1] Légère, A. and Schreiber, M.M. (1989) Competition and Canopy Architecture as Affected by Soybean (Glycine max) Row Width and Density of Redroot Pigweed (Amaranthus retroflexus). Weed Science, 37, 84-92. https://doi.org/10.1017/S0043174500055909

[2] Klingaman, T.E. and Oliver, L.R. (1994) Palmer Amaranth (Amaranthus palmeri) Interference in Soybeans (Glycine max). Weed Science, 42, 523-527. https://doi.org/10.1017/S0043174500076888

[3] Knezevic, S.Z., Weise, S.F. and Swanton, C.J. (1994) Interference of Redroot Pigweed (Amaranthus retroflexus) in Corn (Zea mays). Weed Science, 42, 568-573. https://doi.org/10.1017/S0043174500076967

[4] Ma, X., Wu, H., Jiang, W., Ma, Y. and Ma, Y. (2015) Interference between Redroot Pigweed (Amaranthus retroflexus L.) and Cotton (Gossypium hirsutum L.): Growth Analysis. PLoS ONE, 10, e0130475. https://doi.org/10.1371/journal.pone.0130475

[5] Heap, I. (2020) The International Survey of Herbicide-Resistant Weed Database. https://www.weedscience.org

[6] Wax, L.M. (1995) Pigweeds of the Midwest-Distribution, Importance and Management. Proceedings of the Integrated Crop Management Conference, Iowa State University, Ames, Iowa, 29-30 November 1995, 239-242.

https://doi.org/10.31274/icm-180809-512

[7] Weaver, S.E. and McWilliams, E.L. (1980) The Biology of Canadian Weeds: 44. Amaranthus retroflexus L., A. powellii S. Wats. and A. hybridus L. Canadian Journal of Plant Science, 60, 1215-1234. https://doi.org/10.4141/cjps80-175

[8] Costea, F.J. and Tardif, M. (2003) The Biology of Canadian Weeds. 126. Amaranthus albus L., A. blitoides S. Watson and A. blitum L. Canadian Journal of Plant Science, 83, 1039-1066. https://doi.org/10.4141/P02-056

[9] Mitchell, J. and Rook, A. (1979) Botanical Dermatology: Plants and Plant Products Injurious to the Skin. Greengrass, Vancouver, Canada.

[10] Würtzen, P.A., Nelson, H.S., Løwenstein, H. and Ipsen, H. (1995) Characterization of Chenopodiales (Amaranthus retroflexus, Chenopodium album, Kochia scoparia, Salsola pestifer) Pollen Allergens. Allergy, 50, 489-497.

https://doi.org/10.1111/j.1398-9995.1995.tb01184.x

[11] Horak, M.J., Peterson, D.E., Chessman, D.J. and Wax, L.M. (2019) Pigweed Identification: A Pictorial Guide to the Common Pigweeds of the Great Plains. Kansas State University, Manhattan, KS, 13.

[12] Haboudane, D., Miller, J.R., Pattey, E., Zarco-Tejada, P.J. and Strachan, I.B. (2004) Hyperspectral Vegetation Indices and Novel Algorithms for Predicting Green LAI of Crop Canopies: Modeling and Validation in the Context of Precision Agriculture. Remote Sensing of Environment, 90, 337-352. https://doi.org/10.1016/j.rse.2003.12.013

[13] Bian, M., Skidmore, A.K., Schlerf, M., Fei, T., Liu, Y. and Wang, T. (2010) Reflectance Spectroscopy of Biochemical Components as Indicators of Tea (Camellia sinensis) Quality. Photogrammetric Engineering and Remote Sensing, 76, 1385-1392. https://doi.org/10.14358/PERS.76.12.1385 
[14] Pott, L.P., Amado, T.J., Schwalbert, R.A., Sebem, E., Jugulam, M. and Ciampitti, I.A. (2020) Pre-Planting Weed Detection Based on Ground Field Spectral Data. Pest Management Science, 76, 1173-1182. https://doi.org/10.1002/ps.5630

[15] Pu, R. and Gong, P. (2011) Hyperspectral Remote Sensing of Vegetation Bioparameters. In: Weng, Q.H., Ed., Advances in Environmental Remote Sensing: Sensors, Algorithm, and Applications, CRC Press, Boca Raton, 101-142. https://doi.org/10.1201/b10599-11

[16] Roberts, D., Roth, K. and Perroy, R. (2011) Hyperspectral Vegetation Indices. In: Thenkabail, P.S. and Lyon, J.G., Eds., Hyperspectral Remote Sensing of Vegetation, CRC Press, Boca Raton, 309-327.

[17] Pu, R. (2017) Hyperspectral Remote Sensing: Fundamentals and Practices. CRC Press, Boca Raton. https://doi.org/10.1201/9781315120607

[18] Green, K., Congalton, R.G. and Tukman, M. (2017) Imagery and GIS: Best Practices for Extracting Information from Imagery. Esri Press, Redlands, CA.

[19] Thenkabail, P., Gumma, M., Teluguntla, P. and Ahmed, M.I. (2014) Hyperspectral Remote Sensing of Vegetation and Agricultural Crops. Photogrammetric Engineering and Remote Sensing, 80, 697-709.

[20] Thenkabail, P., Mariotto, I., Gumma, M., Middleton, E., Landis, D. and Huemmrich, K. (2013) Selection of Hyperspectral Narrowbands (HNBs) and Composition of Hyperspectral Twoband Vegetation Indices (HVIs) for Biophysical Characterization and Discrimination of Crop Types Using Field Reflectance and Hyperion/EO-1 Data. IEEE Journal of Selected Topics in Applied Earth Observations and Remote Sensing, 6, 427-439. https://doi.org/10.1109/JSTARS.2013.2252601

[21] Galvão, L., Epiphanio, J., Breunig, F. and Formaggio, A. (2011) Crop Type Discrimination Using Hyperspectral Data. In: Thenkabail, P.S. and Lyon, J.G., Eds., Hyperspectral Remote Sensing of Vegetation, CRC Press, Boca Raton, 397-421.

[22] Gitelson, A. (2011) Non-Destructive Estimation of Foliar Pigment (Chlorophylls, Carotenoids and Anthocyanins) Contents: Espousing a Semi-Analytical Three-Band Model. In: Thenkabail, P.S. and Lyon, J.G., Eds., Hyperspectral Remote Sensing of Vegetation, CRC Press, Boca Raton, 141-166.

[23] Gamon, J.A., Serrano, L. and Surfus, J.S. (1997) The Photochemical Reflectance Index: An Optical Indicator of Photosynthetic Radiation Use Efficiency across Species, Functional Types, and Nutrient Levels. Oecologia, 112, 492-501. https://doi.org/10.1007/s004420050337

[24] Trotter, G.M., Whitehead, D. and Pinkney, E.J. (2002) The Photochemical Reflectance Index as a Measure of Photosynthetic Light Use Efficiency for Plants with Varying Foliar Nitrogen Contents. International Journal of Remote Sensing, 23, 1207-1212. https://doi.org/10.1080/01431160110106096

[25] Middleton, E.M., Huemmrich, K.F., Cheng, Y.B. and Margolis, H. (2011) Spectral Bioindicators of Photosynthetic Efficiency and Vegetation Stress. In: Thenkabail, P.S. and Lyon, J.G., Eds., Hyperspectral Remote Sensing of Vegetation, CRC Press, Boca Raton, 265-288.

[26] Danner, M., Locherer, M., Hank, T. and Richter, K. (2015) En Map Field Guides Technical Report Spectral Sampling with the ASD FIELDSPEC 4. GFZ Data Services.

http://gfzpublic.gfz-potsdam.de/pubman/item/escidoc:1388298/component/escidoc: 1388299/EnMAP_FieldGuide_ASD_2015_008.pdf

[27] Fletcher, R.S. and Turley, R.B. (2018) Comparing Canopy Hyperspectral Reflectance Properties of Palmer Amaranth to Okra and Super-Okra Leaf Cotton. American 
Journal of Plant Sciences, 9, 2708-2718. https://doi.org/10.4236/ajps.2018.913197

[28] Savitzky, A. and Golay, M.J.E. (1964) Smoothing and Differentiation of Data by Simplified Least Squares Procedures. Analytical Chemistry, 36, 1627-1639. https://doi.org/10.1021/ac60214a047

[29] R Core Team (2020) R: A Language and Environment for Statistical Computing. R Foundation for Statistical Computing, Vienna, Austria. https://www.r-project.org/

[30] Lehnert, L., Meyer, H., Obermeier, W., Silva, B., Regeling, B., Thies, B. and Bendix, J. (2019) Hyperspectral Data Analysis in R: The Hsdar Package. Journal of Statistical Software, 89, 1-23. https://doi.org/10.18637/jss.v089.i12

[31] Thenkabail, P., Ed. (2018) Hyperspectral Remote Sensing for Terrestrial Applications. In: Thenkabail, P., Ed., Remote Sensing Handbook-Three Volume Set, CRC Press, Boca Raton, 935-968. https://doi.org/10.1201/b19355-70

[32] Jensen, J.R. (2016) Introductory Digital Image Processing: A Remote Sensing Perspective. Prentice Hall Press, Upper Saddle River, NJ.

[33] Stanberry, L. (2013) Analysis of Variance. In: Dubitzky, W., Wolkenhauer, O., Cho, K.H. and Yokota, H., Eds., Encyclopedia of Systems Biology, Springer, New York, NY, 24-25. https://doi.org/10.1007/978-1-4419-9863-7_1193

[34] Haynes, W. (2013) Tukey's Test. In: Dubitzky, W., Wolkenhauer, O., Cho, K.H. and Yokota, H., Eds., Encyclopedia of Systems Biology, Springer, New York, NY, 2303-2304. https://doi.org/10.1007/978-1-4419-9863-7_1212

[35] De Mendiburu, F. and Simon, R. (2015) Agricolae-Ten Years of an Open Source Statistical Tool for Experiments in Breeding, Agriculture and Biology. PeerJ, 3, e1404v1. https://doi.org/10.7287/peerj.preprints.1404v1

[36] De Mendiburu, F. (2020) Agricolae: Statistical Procedures for Agricultural Research. https://CRAN.R-project.org/package=agricolae

[37] Huete, A.R. (2004) 11-Remote Sensing for Environmental Monitoring. In: Artiola, J.F., Pepper, I.L. and Brusseau, M.L., Eds., Environmental Monitoring and Characterization, Academic Press, Burlington, 183-206. https://doi.org/10.1016/B978-012064477-3/50013-8

[38] Lemaire, G., Francois, C., Soudani, K., Berveiller, D., Pontailler, J., Breda, N., Genet, H., Davi, H. and Dufrene, E. (2008) Calibration and Validation of Hyperspectral Indices for the Estimation of Broadleaved Forest Leaf Chlorophyll Content, Leaf Mass per Area, Leaf Area Index and Leaf Canopy Biomass. Remote Sensing of Environment, 112, 3846-3864. https://doi.org/10.1016/j.rse.2008.06.005

[39] Pena-Barragan, J.M., Lopez-Granados, F., Jurado-Exposito, M. and Garcia-Torres, L. (2006) Spectral Discrimination of Ridolfia segetum and Sunflower as Affected by Phenological Stage. Weed Research, 46, 10-21. https://doi.org/10.1111/j.1365-3180.2006.00488.x 